\title{
Educação infantil e currículo: uma análise da proposta da rede municipal de Curitiba, PR
}

\section{Child education and curriculum: an analysis of municipal network proposal of Curitiba, PR}

\author{
Educación infantil y currículo: un análisis de la \\ propuesta de la red municipal de Curitiba, PR
}

Romilda Teodora Ens ${ }^{1}$

Jaqueline Salanek de Oliveira Nagel ${ }^{2}$

Édina Dayane de Lara Bueno ${ }^{3}$

DOI: http://dx.doi.org/10.20435/serie-estudos.v23i49.1136

\begin{abstract}
Resumo: O presente artigo apresenta uma reflexão acerca do documento "Educação Infantil: Caderno I - princípios e fundamentos" da Rede Municipal de Ensino de Curitiba (RMEC), que norteia o currículo da Educação Infantil no município. A pesquisa buscou verificar a relação entre o documento da RMEC com a versão final da Base Nacional Curricular Comum (BNCC) e as Diretrizes Curriculares para a Educação Infantil (DCNEI) no que diz respeito ao currículo e ao processo de avaliação, bem como analisar como são sugeridas essas práticas na RMEC. O suporte da análise crítica do discurso de Fairclough (2001; 2012) e "Decifrar textos para compreender a política: subsídios teórico-metodológicos para análise de documentos" de Shiroma, Campos e Garcia (2005) subsidiaram esta pesquisa documental, possibilitando inferir que o documento que contempla a proposta de Educação Infantil para a Rede Municipal de Ensino de Curitiba assegura as especificidades para essa modalidade de ensino. A construção do documento que norteia a RMEC foi coletiva, expondo a concepção de currículo e avaliação na Educação Infantil defendida, além de propor a organização e estruturação para que se efetive um trabalho nas escolas e centro de educação infantil desse município.
\end{abstract}

Palavras-chave: Educação Infantil; documentos oficiais; currículo e avaliação.

Abstract: This paper presents a reflection about the document "Child Education: Notebook I principles and fundamentals" of the Municipal Education Network of Curitiba (RMEC), which guides the curriculum of Early Childhood Education in the municipality. The research sought to verify the relationship between the RMEC document with the final version of the National

\footnotetext{
${ }^{1}$ Pontifícia Universidade Católica do Paraná, Curitiba, Paraná, Brasil.

2 Prefeitura Municipal de Curitiba, Curitiba, Paraná, Brasil.

${ }_{3}^{3}$ Pontifícia Universidade Católica do Paraná, Curitiba, Paraná, Brasil.
} 
Curricular Common Base (BNCC) and the Curriculum Guidelines for Early Childhood Education (DCNEI) regarding curriculum and evaluation process, as well as to analyze how these practices are suggested in the RMEC. The support of the critical analysis of Fairclough's discourse $(2001 ; 2012)$ and "Deciphering texts to understand politics: theoretical-methodological subsidies for document analysis" by Shiroma, Campos and Garcia (2005) subsidized this documentary research, making it possible to infer that the document which contemplates the proposal of Child Education for the Municipal Network of Education of Curitiba assures the specifics for this modality of education. The construction of the document which guides the RMEC was collective, exposing the conception of curriculum and evaluation in the Child Education defended, besides proposing the organization and structuring so that a work in the schools and in early childhood education centers of this municipality.

Keywords: Child Education; official documents; curriculum and evaluation.

Resumen: Este artículo presenta una reflexión sobre el documento "Educación Infantil: Cuaderno I- principios y fundamentos" de la Red Municipal de Educación de Curitiba (RMEC), que orienta el currículo de Educación Infantil en el municipio. La investigación buscó verificar la relación entre el documento de RMEC con la versión final de la Base Común Curricular Nacional (BNCC) y las Directrices Curriculares para la Educación Infantil (DCNEI) con respecto al currículo y proceso de evaluación, así como analizar cómo estas prácticas son sugeridas en el RMEC. El apoyo del análisis crítico del discurso de Fairclough $(2001 ; 2012)$ y "Descifrar textos para entender la política: subsidios teórico-metodológicos para el análisis de documentos" por Shiroma, Campos y García (2005) subsidió esta investigación documental, permitiendo inferir que el documento que contempla la propuesta de Educación Infantil para la Red Municipal de Educación de Curitiba asegura las especificidades de esta modalidad de educación. La construcción del documento que guía a la RMEC fue colectiva, exponiendo la concepción de currículo y evaluación en la Educación Infantil defendida, además de proponer la organización y estructuración para que tenga lugar una obra en las escuelas y en centros de educación infantil en ese municipio.

Palabras clave: Educación Infantil; documentos oficiales; currículo y evaluación.

\section{INTRODUÇÃO}

No Brasil, a Educação Infantil é a primeira etapa da Educação Básica, na qual são atendidas crianças entre 0 a 5 anos de idade. Neste artigo, realizamos uma análise do documento "Educação Infantil Caderno I: princípios e fundamentos" (2016) da Rede Municipal de Ensino de Curitiba acerca da concepção de currículo e avaliação nessa modalidade e sua relação com a versão final da Base Nacional Curricular Comum (BNCC) (BRASIL, 2017) e as Diretrizes Curriculares para a Educação Infantil (DCNEI) (BRASIL, 2009a) no que diz respeito ao currículo e ao processo de avaliação, bem como analisamos como são sugeridas essas práticas.

O suporte da Análise Crítica do Discurso (ACD) proposta por Fairclough (2012) marcou parte da análise documental, no que considera a linguagem como "elemento integrante do processo social material" (p. 308), e fornece indícios 
para a construção de critérios fundamentais para a análise do discurso que o documento apresenta na realidade do contexto retratado. Ou seja, tomamos esse documento, como afirmam Shiroma, Campos e Garcia (2005, p. 427) “[...] aberto a re-leituras, não um objeto para consumo passivo, mas um objeto a ser trabalhado pelo pesquisador para produzir sentido".

A indicação da posição adotada para a análise dos textos selecionados, por reconhecê-los "[...] como produtos e produtores de orientações políticas" (SHIROMA; CAMPOS; GARCIA, 2005, p. 427), tomamos como ponto de partida da análise algumas considerações pertinentes ao conceito histórico e político da Educação Infantil, a partir do destaque da concepção de infância e criança para o desenvolvimento de estudos acerca do tema. Na sequência é discutida a construção do documento "Educação Infantil Caderno I - princípios e fundamentos". No próximo item, são expostas as concepções de currículo e avaliação na Educação Infantil, tendo por apoio teóricos como Hoffmann (2015), Pérez (2013) e Kramer (2007; 1987), selecionado como foco o discurso sobre o processo de avaliação e acerca da concepção de currículo, indicados nesse documento.

\section{METODOLOGIA}

Nesta pesquisa, não pretendemos fazer uma análise crítica do discurso, mas compreender a proposta para Educação Infantil, estabelecida no "Caderno I: princípios e fundamentos" (2016). É fato que a análise discursiva documental nos possibilita compreender fenômenos que emergem do discurso proposto no texto sob análise. De acordo com Moraes (2003, p. 192), a análise textual qualitativa "pode ser compreendida como um processo auto-organizado de construção de compreensão em que novos entendimentos emergem de uma sequência recursiva". Esse tipo de análise permite a estruturação de novos significados ao conteúdo do documento, apontando silenciamentos e pertencimentos na análise do texto.

Fairclough (2012, p. 308) estabelece que a análise crítica do discurso (ACD) propicia o exame das interfaces do texto com as práticas sociais. É importante destacar os elementos que compõem essa prática: a atividade produtiva; os meios de produção; as relações sociais; as identidades sociais; os valores culturais; a consciência e a semiose, que é a produção de significado. Esses elementos estão conectados entre si, mantendo sua singularidade, mas não separados e divergentes (FAIRCLOUGH, 2012). 
Singulariza a posição da ACD, no que esta "combina uma apreciação negativa, no diagnóstico do problema, com uma apreciação positiva, na identificação das possibilidades até então inconcebidas para sua resolução, levando em consideração a maneira como as coisas estão" (FAIRCLOUGH, 2012, p. 312).

Por sua vez, é preciso estar atento quando da re-leitura de quaisquer textos políticos, pois estes são caracterizados por um tom prescritivo e recorrem a um argumento de autoridade, dando

[...] margem a interpretações e reinterpretações, gerando, como consequência, atribuição de significados e de sentidos diversos a um mesmo termo. Esses significados e sentidos apresentam-se, não raro, em competição com outros veiculados por outros textos e outros discursos. (SHIROMA; CAMPOS; GARCIA, 2005, p. 427).

Complementando, as autoras afirmam que os textos políticos são

[...] caracterizados por um tom prescritivo e recorrendo a argumento de autoridade, os textos da política dão margem a interpretações e reinterpretações, gerando, como consequência, atribuição de significados e de sentidos diversos a um mesmo termo. Esses significados e sentidos apresentam-se, não raro, em competição com outros veiculados por outros textos e outros discursos. (SHIROMA; CAMPOS; GARCIA, 2005, p. 431)

Embora Fairclough (2001, p. 105) destaque que a análise proposta seja capaz de investigar a prática social como algo que se produz ativamente, ele alude que tanto "[...] o sentido da palavra, particularmente, como os sentidos das palavras entram em disputa dentro de lutas mais amplas", quando "[...] as estruturações particulares das relações entre as palavras e das relações entre os sentidos de uma palavra são formas de hegemonia".

Com base nessas orientações, procuramos compreender o texto do documento "Educação Infantil Caderno I: princípios e fundamentos" (CURITIBA, 2016) da Rede Municipal de Ensino de Curitiba acerca da concepção de currículo e avaliação nessa modalidade e de suas relações com a versão final da Base Nacional Curricular Comum (BNCC) (BRASIL, 2017) e as Diretrizes Curriculares para a Educação Infantil (DCNEI) (BRASIL, 2009c). Haja vista que, como orientam Bowe e Ball (1992 apud SHIROMA; CAMPOS; GARCIA, 2005, p. 427), os textos precisam "ser lidos em relação ao tempo e particular contexto em que foram produzidos e também devem ser confrontados a outros do mesmo período e local". 
Na continuidade, para melhor compreender, situamos e desvelamos o percurso histórico e as políticas que definiram o modelo proposto para a Educação Infantil em Curitiba.

\section{CONSIDERAÇÕES SOBRE A EDUCAÇÃO INFANTIL: PERCURSO HISTÓRICO E AS POLÍTICAS PÚBLICAS}

O processo histórico da trajetória de oferta da Educação Infantil imbrica-se com a concepção de infância predominante em cada tempo e espaço. Para analisar quaisquer aspectos da oferta da Educação Infantil, é necessário conhecer o contexto no qual os conceitos relacionados estejam inseridos, nomeadamente os de infância e criança, porque foram e continuam sendo trespassados por sentidos diferentes. A trajetória da Educação Infantil é modificada pela conjunção particular de fatores de ordem econômica, social e política, predominante em um dado tempo e espaço cultural, dentre esses, os ideológicos que afetam a evolução dos conceitos sobre infância e da própria criança (PÉREZ, 2013).

Concepções de infância são marcadas por diferentes perspectivas sobre criança seja, como a "[...] de um indivíduo que precisa ser treinado, conduzido e controlado, [...ou pela] de alguém ingênuo, que deva ser paparicado, protegido e cuidado" (FAVORETO, 2013, p. 29). Sobre a infância, Kramer (2007, p. 13) indica, ainda, que infância pode ser entendida a partir de duas perspectivas: a primeira, como uma categoria social e da história humana, e a segunda, como um "período da história de cada um, que se estende, na nossa sociedade, do nascimento até aproximadamente dez anos de idade". Nesse viés, torna-se indispensável contextualizar questões referentes à situação política e econômica da sociedade para a compreensão do conceito de infância e de criança, pois esses conceitos

[...] variam com as formas de organização da sociedade, o que explica porque a ideia de infância não existiu sempre e da mesma maneira, mas é percebida pela sociedade de forma diversificada ao longo do tempo, de acordo com as relações de produção vigentes em cada época. (FAVORETO, 2013, p. 29).

No decorrer do século XX, os estudos sobre a criança foram ampliados, nomeadamente a partir de quando "Phillipe Ariès publicou, nos anos 1970, seu estudo sobre a história social da criança e da família, analisando o surgimento da noção de infância na sociedade moderna" (KRAMER, 2007, p. 14). Desde então, a concepção de educação de crianças ganhou forte influência de diferentes campos 
de investigação, dentre eles estão a biologia, que demonstrou as necessidades básicas da criança como requisito para a aprendizagem, a psicologia, que, por exemplo, descreveu a evolução e desenvolvimento cognitivo desde seu nascimento (PIAGET; INHELDER, 2003), da sociologia em um de seus ramos - sociologia da infância (SARMENTO, 2011). Kramer (1987, p. 27) ressalta que:

A educação pré-escolar começou a ser reconhecida como necessária tanto na Europa quanto nos Estados Unidos durante a depressão econômica dos anos 30. Seu principal objetivo era o de garantir emprego a professores, enfermeiros e outros profissionais e, simultaneamente, fornecer nutrição, proteção e um ambiente saudável e emocionalmente estável para crianças carentes de dois a cinco anos de idade.

No Brasil, de um ponto de vista histórico, a partir da década de 1970, a Educação Infantil passou a receber um olhar para além do assistencialismo e, apenas na Constituição de 1988 é que essa modalidade de educação formal passou a ser direito de cada criança e dever do Estado em ofertá-la (HOFFMANN, 2015). Apesar da criança ter sido reconhecida em 1988 como sujeito de direitos no Brasil, somente na Lei de Diretrizes e Bases da Educação, LDB 9.394/1996 a educação e cuidado foram inscritos em um texto legal e considerados como função da Educação Infantil, entendendo que essas funções eram exercidas anteriormente de forma fragmentada e predominantemente assistencialista (BRASIL, 1988; 1996). Desde então, o atendimento a crianças pequenas passou a ser feito em creches e centros de Educação Infantil, sob o princípio de direito, já ressaltado no Estatuto da Criança e do Adolescente, aprovado em 13 de junho de 1990 (BRASIL, 1990).

A Lei de Diretrizes e Bases da Educação (LDB) n. 9.394/1996, nos artigos 29, 30 e 31, regulamenta a Educação Infantil como a primeira etapa da Educação Básica, indicando como sua finalidade a de promover o desenvolvimento integral da criança de 0 a 5 anos de idade, como um direito da família e da criança e um dever do Estado. Em 2013, quando promulgada a Lei n. 12.796/2013, a qual altera a Lei n. 9.394/1996, estabeleceu que as crianças com 4 anos devem ser matriculadas na Educação Infantil. Com isso, a Educação Infantil passa a fazer parte da educação básica e terá uma organização conforme o estabelecido no art. 31 .

Art. 31. A educação infantil será organizada de acordo com as seguintes regras comuns: 
I - avaliação mediante acompanhamento e registro do desenvolvimento das crianças, sem o objetivo de promoção, mesmo para o acesso ao ensino fundamental;

II- carga horária mínima anual de 800 (oitocentas) horas, distribuída por um mínimo de 200 (duzentos) dias de trabalho educacional;

III- atendimento à criança de, no mínimo, 4 (quatro) horas diárias para o turno parcial e de 7 (sete) horas para a jornada integral;

IV- controle de frequência pela instituição de educação pré-escolar, exigida a frequência mínima de 60\% (sessenta por cento) do total de horas;

$V$ - expedição de documentação que permita atestar os processos de desenvolvimento e aprendizagem da criança. (NR). (BRASIL, 2013).

As crianças brasileiras, a partir de 2013, tiveram o direito à matrícula obrigatória na educação básica a partir dos quatro anos de idade. Para atender essa obrigatoriedade, a responsabilidade da matrícula coube aos pais e responsáveis apesar de as redes municipais e estaduais de ensino terem até 2016 para se adequarem e acolher alunos de 4 a 17 anos.

Desse momento em diante, a Educação Infantil passou a integrar oficialmente a Educação Básica, no que validou sua função educativa e deu início à constituição de sua identidade, enquanto modalidade de ensino. As diretrizes acerca da criança como sujeito de direitos, assim estatuídas oficialmente passaram a ser amplamente discutidas no seio social e acadêmico, no que articulam a Educação Infantil à Educação Básica, e evidenciam seu papel, qual seja o de "iniciar a formação necessária a que toda pessoa tem direito para o exercício da cidadania, recebendo os conhecimentos básicos que são necessários para a continuidade dos estudos posteriores" (OLIVEIRA, 2002, p. 37).

Sob essa perspectiva, cabe particularmente aos sistemas de ensino, público e privado, se centrarem em promover a formação da criança de maneira integrada, considerando seus aspectos físicos, psicológicos, sociais e intelectuais como fatores que visam ao desenvolvimento integral da criança.

De uma forma geral, as políticas públicas voltadas à Educação Infantil - assim como muitas outras - apresentam uma lacuna entre o texto que as estatuem, pela promulgação de leis e outros atos, e no que geram pelo descompasso entre as "diretrizes amplas e a ausência de previsão de mecanismos operacionais efetivos que garantam a aplicação daqueles princípios na realidade, na direção 
implícita nos objetivos gerais" (CAMPOS, 2002, p. 28). A apropriação das legislações educacionais brasileiras, por parte dos agentes e professores de Educação Infantil, no contexto específico no qual essa modalidade de ensino ocorre, ainda aparece precária, apesar da ampla discussão nos meios acadêmicos.

Como um dos focos deste trabalho é o da análise do documento "Educação Infantil Caderno I - Princípios e Fundamentos da Educação Infantil", Iançado ao final do ano de 2016, como instrumento de política do sistema municipal de ensino do município de Curitiba para a Educação Infantil, passaremos a sua análise.

\section{A CONSTRUÇÃO DO DOCUMENTO: EDUCAÇÃO INFANTIL CADERNO I- PRINCÍPIOS E FUNDAMENTOS}

A síntese da trajetória da oferta da Educação Infantil no município de Curitiba (Quadro 1), contextualiza o espaço e tempo da proposição do documento "Educação Infantil I - Caderno I: princípios e fundamentos" proposto para esse município em 2016.

Quadro 1 - Linha do tempo da Educação Infantil em Curitiba

\begin{tabular}{|c|c|}
\hline ANO/PERÍODO & FATOS \\
\hline 1929 & $\begin{array}{l}\text { Surgimento da primeira creche comunitária "Escola Maternal da Sociedade } \\
\text { Socorro aos necessitados". }\end{array}$ \\
\hline 1968 & $\begin{array}{l}\text { Atendimento Pré-escolar a uma pequena parcela da população, } \\
\text { considerado como preparatório para o ensino fundamental. }\end{array}$ \\
\hline 1975 & $\begin{array}{l}\text { A educação infantil tinha caráter compensatório, modelo que visava treino } \\
\text { de habilidades e atitudes e aos exercícios de coordenação motora. }\end{array}$ \\
\hline 1976 & $\begin{array}{l}\text { Primeiros incentivos do poder público Municipal para a construção de } \\
\text { creches. }\end{array}$ \\
\hline 1977 & $\begin{array}{l}\text { Inauguradas as } 4 \text { primeiras creches públicas municipais: Vila Camargo, } \\
\text { Jardim Paranaense, Vila Hauer e Xaxim. }\end{array}$ \\
\hline 1979 & Existência de 34 turmas de pré-escola (faixa etária de cinco a seis anos). \\
\hline 1980 & $\begin{array}{l}\text { Discussão do processo de criação de uma rede municipal de creches, de } \\
\text { maneira integrada entre IPPUC e Departamento de Desenvolvimento Social, } \\
\text { resultando numa proposta que previa a definição de critérios e parâmetros } \\
\text { para a expansão das creches, denominada "Módulo de Atendimento } \\
\text { Infantil". O olhar cuidadoso para a criança neste momento aparece, como } \\
\text { programas para melhorar a alimentação, creches de vizinhança etc. }\end{array}$ \\
\hline 1984 & $\begin{array}{l}\text { Surgimento de Creches Comunitárias, Creches Vizinhanças, gerenciadas } \\
\text { pelas Associações de Moradores das comunidades onde estavam inseridas. }\end{array}$ \\
\hline
\end{tabular}




\begin{tabular}{|c|c|}
\hline ANO/PERÍODO & FATOS \\
\hline 1985 & $\begin{array}{l}\text { Realização dos primeiro concurso público para a contratação de } \\
\text { funcionários para creches. }\end{array}$ \\
\hline 1986 & $\begin{array}{l}\text { Elaboração do manual de Orientações Técnico-Administrativas do Programa } \\
\text { Creche. }\end{array}$ \\
\hline 1987 & $\begin{array}{l}\text { Novos concursos para: babá, administrador, cozinheira, auxiliar de cozinha e } \\
\text { servente. }\end{array}$ \\
\hline 1988 & $\begin{array}{l}\text { Promulgada a Constituição de 1988, que definiu a criança como cidadã de } \\
\text { direitos. }\end{array}$ \\
\hline 1989 & $\begin{array}{l}\text { Criada a Secretaria Municipal da Criança (SMCr) e consolidada a organizaçãc } \\
\text { do Programa Creche em Curitiba. }\end{array}$ \\
\hline $1970 / 1990$ & $\begin{array}{l}\text { Construídas } 108 \text { creches. } \\
\text { O projeto Araucária - Programa de Extensão da Universidade Federal } \\
\text { do Paraná (UFPR) - implantado na RME em 1985, teve por o objetivo } \\
\text { direcionar a implantação de uma proposta pedagógica para o trabalho com } \\
\text { as crianças de } 4 \text { a } 6 \text { anos, desenvolvendo cursos de aperfeiçoamento para } \\
\text { os profissionais da Educação Infantil. }\end{array}$ \\
\hline 1990 & $\begin{array}{l}\text { Promulgado o Estatuto da Criança e do Adolescente (ECA), reafirmando a } \\
\text { criança como cidadã de direitos. }\end{array}$ \\
\hline 1994 & $\begin{array}{l}\text { Elaborada a proposta Pedagógica para o trabalho com crianças de } 0 \text { a } 6 \\
\text { anos pela Secretaria Municipal da Criança (SMCr). }\end{array}$ \\
\hline 1996 & $\begin{array}{l}\text { Promulgada a Lei de Diretrizes e Bases da Educação Nacional (LDBEN) n. } \\
\text { 9.394/1996. }\end{array}$ \\
\hline 1998 & $\begin{array}{l}\text { O MEC lança o Referencial Curricular Nacional para a Educação Infantil } \\
\text { (RCNEI), com o intuito de sintetizar uma prática pedagógica para a Educação } \\
\text { Infantil. }\end{array}$ \\
\hline 1999 & $\begin{array}{l}\text { O Departamento de atendimento infantil da SMCr deu início ao processo de } \\
\text { discussão acerca da revisão e reescrita da proposta pedagógica, em conjunto } \\
\text { com (psicólogos, pedagogos, assistentes sociais), atuantes nas creches. }\end{array}$ \\
\hline 2000 & $\begin{array}{l}\text { O atendimento de crianças de } 6 \text { anos, antes atendidas em creches, passou } \\
\text { para escolas municipais, devido a implantação dos Ciclos de Aprendizagem } \\
\text { na RMEC, em que a pré-escola passou a compor a etapa inicial do Ciclo I. }\end{array}$ \\
\hline 2001 & $\begin{array}{l}\text { Aproximação entre a SMCr e a SME para a discussão sobre a atualização } \\
\text { da proposta pedagógica. Decreto n. 55/2001, da Prefeitura Municipal de } \\
\text { Curitiba, o qual altera a nomenclatura de creche municipal para Centro } \\
\text { Municipal de Educação Infantil (CMEI) (CURITIBA, 2001). }\end{array}$ \\
\hline 2003 & $\begin{array}{l}\text { CMEIs deixam de ser responsabilidade da SMCr e passam a integrar a SME. } \\
\text { Esta mudança alterou o quadro funcional, (o pedagogo passa a compor o } \\
\text { quadro dos profissionais dos CMEIs). }\end{array}$ \\
\hline
\end{tabular}




\begin{tabular}{|c|l|}
\hline ANO/PERÍODO & \multicolumn{1}{c|}{ FATOS } \\
\hline 2004 & $\begin{array}{l}\text { Inicia-se a atuação do Instituto Avisa-Lá4 em duas unidades de educação } \\
\text { infantil: CMEI Solitude e o CEI conveniado Casa da Criança em São José. } \\
\text { Início da implantação dos Conselhos nos CMEls. }\end{array}$ \\
\hline 2005 & $\begin{array}{l}\text { Discussões para a redação das Diretrizes Curriculares na RME de Curitiba. } \\
\text { Ampliação da parceria entre a SME com o Instituto Avisa-Lá nas formações } \\
\text { da educação infantil. }\end{array}$ \\
\hline \multirow{2}{*}{2006} & $\begin{array}{l}\text { Lançamento do Projeto Família, que busca integração entre as famílias e } \\
\text { instituição de Educação Infantil. Implementação das Diretrizes Curriculares } \\
\text { para a Educação Municipal de Curitiba, no qual o volume 2 é sobre a } \\
\text { Educação Infantil. }\end{array}$ \\
\hline \multirow{2}{*}{2008} & $\begin{array}{l}\text { Lançamento do Programa Mama Nenê, uma parceria entre a SME e a } \\
\text { Secretaria Municipal da Saúde (SMS), que tem por objetivo incentivar e } \\
\text { promover o aleitamento materno nas instituições que ofertam Educação } \\
\text { Infantil. Realização do 10 Seminário de Educaça Infantil. }\end{array}$ \\
\hline \multirow{2}{*}{2009} & $\begin{array}{l}\text { Parceria entre a PMC e a empresa IBM, visando a inclusão digital } \\
\text { de crianças e profissionais. Início dos projetos “Educamovimento" e } \\
\text { "Ampliando Horizontes". Lançamento do Caderno Pedagógico de Oralidade. }\end{array}$ \\
\hline \multirow{2}{*}{2010} & $\begin{array}{l}\text { Aprovado parecer CNE/CEB n. 20/2009 - Revisão das Diretrizes Curriculares } \\
\text { Nacionais para a Educação Infantil. Elaborados os Cadernos Pedagógicos: } \\
\text { Práticas Inclusivas na Educação Infantil e Movimento. E os Caderno dos } \\
\text { Parâmetros e Indicadores de Qualidade para CMEIS e escolas que ofertam a } \\
\text { Educação Infantil. }\end{array}$ \\
\hline $\begin{array}{l}\text { Elaborados os documentos Referenciais para estudo e planejamento na } \\
\text { Educação Infantil; Diretrizes Curriculares Nacionais para a Educação Infantil } \\
\text { e Rotinas na Educação Infantil - berçários. }\end{array}$ \\
\hline
\end{tabular}

${ }^{4} \mathrm{O}$ Instituto Avisa Lá é uma organização não-governamental (ONG), sem fins lucrativos, com finalidade pública. Desde 1986, vem contribuindo para qualificar a prática pedagógica das redes públicas de Educação Infantil. A partir de 2002, passou atuar também no Ensino Fundamental (séries iniciais) nas áreas de leitura, escrita e matemática. São exemplos dessa contribuição os diferentes programas de formação continuada que atingiram, até o presente momento, por volta de 200 municípios de diferentes estados brasileiros. Vários membros da equipe técnica do Avisa Lá colaboraram intensamente com a elaboração dos Referenciais Curriculares para a Educação Infantil do MEC (1998), com os programas de formação e currículo da Secretaria Municipal de Educação da cidade de São Paulo. O Instituto Avisa Lá participa ativamente de programas do MEC tais como Indique para Educação Infantil e Ensino Fundamental em parceria com a ONG Ação Educativa, Diretrizes em ação em parceria com o UNICEF. Disponível em: <http://avisala. org.br/index.php/quem-somos/>. Acesso em: 15 jun. 2017. 


\begin{tabular}{|c|c|}
\hline ANO/PERÍODO & FATOS \\
\hline 2011 & $\begin{array}{l}\text { Elaborados os documentos: Caderno Pedagógico de Artes para a Educação } \\
\text { Infantil e o Caderno de Parâmetros e Indicadores de Qualidade para os } \\
\text { CEls conveniados com a Prefeitura de Curitiba. Iniciado o projeto músico } \\
\text { da família, em parceria entre as escolas de Educação Infantil e UFPR, com } \\
\text { o intuito de ampliar os saberes musicais e fortalecer a relação entre a } \\
\text { instituição e a família. }\end{array}$ \\
\hline 2012 & $\begin{array}{l}\text { Elaborado o Manual do Conselho para os Centros Municipais de Educação } \\
\text { Infantil. }\end{array}$ \\
\hline 2013 & $\begin{array}{l}\text { Lançamento do Programa Criança Saudável, visando acompanhar os } \\
\text { problemas de saúde e programa saúde na escola. }\end{array}$ \\
\hline 2014 & $\begin{array}{l}\text { Lançamento do Projeto Crianças de Curitiba Criando, com jogos e livros } \\
\text { editados pelas próprias crianças. Realizada primeira edição do Circuito de } \\
\text { Expressão Dramática na Pequena Infância. }\end{array}$ \\
\hline 2015 & $\begin{array}{l}\text { Implantação dos tablets nos CMEls, lançado o projeto Brinca Curitiba } \\
\text { que visa desenvolver ações que mobilizam a reflexão sobre o brincar no } \\
\text { contexto da nossa cidade. Aprovado o Plano Municipal de Educação de } \\
\text { Curitiba. Publicada a primeira versão da Base Nacional Comum Curricular. } \\
\text { Lançado o Projeto Gestão de Resíduos Sólidos nos CMEls e CEls contratados. } \\
\text { Lançado o Projeto Desvendando Contextos: Educação Patrimonial Infância. }\end{array}$ \\
\hline 2016 & $\begin{array}{l}\text { Publicação de documentos: Brinca Curitiba; As experiências das crianças } \\
\text { com a tecnologia na Educação Infantil; Processos de Transição das crianças } \\
\text { da educação infantil: práticas e reflexões; Jogos de tabuleiro na Educação } \\
\text { Infantil e Caderno I - Princípios e Fundamentos da Educação Infantil. } \\
\text { Realizada a realimentação do material do Programa Sinais de Alerta. } \\
\text { Lançamento do Projeto Curitiba Brincante. Realização do décimo seminário } \\
\text { de Educação Infantil. Efetiva-se a universalização da pré-escola para crianças } \\
\text { de } 4 \text { a } 5 \text { anos na RMEC, em virtude da emenda n. 59/2009. } \\
\text { Homologação do documento de "Educação Infantil - Caderno I: princípios e } \\
\text { fundamentos" }\end{array}$ \\
\hline
\end{tabular}

Fonte: As autoras, com base na linha do tempo apresentada no documento "Educação Infantil Caderno I: princípios e fundamentos (CURITIBA, 2016, p. 13-34).

Em 2014, a equipe do Departamento de Educação Infantil em conjunto com os Pedagogos(as) dos núcleos regionais da educação ${ }^{5}$ se reuniram com o intuito

\footnotetext{
${ }^{5}$ A Secretaria Municipal de Educação possui 10 Núcleos Regionais de Educação, responsáveis por operacionar e controlar as atividades de nível central diretamente com as unidades, sejam elas escolas ou Centros Municipais de Educação Infantil. Os 10 Núcleos Regionais são: Bairro Novo, Boa Vista, Boqueirão, Cajuru, CIC, Matriz, Pinheirinho, Portão, Santa Felicidade e Tatuquara.
} 
de estudar os novos documentos nacionais a respeito da Educação Infantil, a fim de analisarem as implicações desse referencial teórico para a formulação da proposta da rede para o município (CURITIBA, 2016).

Após várias discussões, foi elaborada uma síntese em versão preliminar, nomeada "Diretrizes Municipais da Educação Infantil: caderno de estudos", a qual teve como objetivos provocar reflexões e pautar discussões entre os profissionais desse nível de ensino para os olhares, saberes e fazeres que deveriam permear a Educação Infantil na rede municipal de educação. A primeira versão, encaminhada em 2015 para as unidades dessa etapa de ensino, incluiu textos que abordavam uma consigna ou proposição, com o intuito de desencadear o estudo e reflexão sobre a Educação Infantil desenvolvida nas escolas. Assim, as equipes puderam dialogar e discutir se o texto escrito refletia a realidade vivenciada nas instituições de ensino. A partir dessas ponderações e contribuições, após uma reescrita da versão preliminar foi construída a versão atual, intitulada "Caderno I - Princípios e Fundamentos" (CURITIBA, 2016).

O objetivo dessa produção foi o de construir coletivamente um documento que refletisse a escuta do que os profissionais, crianças e familiares envolvidos defendiam para a Educação Infantil da RME de Curitiba. A validação desse documento ocorreu em 2016, quando esses profissionais que atuavam direta ou indiretamente na Educação Infantil da RME (unidades, núcleos regionais e Departamentos de Educação Infantil) chegaram a uma convergência do que se espera da Educação Infantil na RME, sua intencionalidade e função. As orientações para essa etapa foram organizadas para compor dois cadernos, um com os princípios e fundamentos (Caderno I) e outro ainda em construção (Caderno II) "que abordará a organização curricular estruturada por campos de experiência, articulando os princípios, as condições e os objetivos propostos para a Educação Infantil" (CURITIBA, 2016).

O Caderno I - Princípios e fundamentos está organizado em escritos que versam a identidade, função sociopolítica e pedagógica da Educação Infantil; princípios éticos, políticos e estéticos; visão de criança; salientamos a importância do constante diálogo entre família e instituição; dos objetivos e condições para a organização curricular, bem como sobre o currículo e, por fim, da avaliação e sua importância (CURITIBA, 2016). 


\section{PERSPECTIVAS DE CURRÍCULO E AVALIAÇÃO NA EDUCAÇÃO INFANTIL}

Consideramos o currículo como documento norteador que define o que é significativo ao processo de ensino-aprendizagem. Temos claro, que o currículo como afirma Eyng (2015, p. 136) não poderá ser "uma miscelânea de concepções sobre currículo e avaliação [...], dos quais alguns fragmentos são pinçados, unidos a outros e aplicados, sem a necessária análise crítica e contextualizada".

Pensar em um currículo para a Educação Infantil na realidade brasileira é refletir acerca da identidade e das políticas públicas vigentes, especialmente porque, "para o sistema educacional brasileiro, é uma experiência completamente nova essa de acolher crianças tão pequenas, especialmente os bebês. Além disso, de assumir a integração entre educar e cuidar" (ROSEMBERG, 2010, p. 173).

O Parecer CNE/CEB n. 20/2009 e a Resolução CNE/CEB n. 05/2009 regulamentam as Diretrizes Curriculares Nacionais para a Educação Infantil (BRASIL, 2009b; 2009c), definindo um "currículo e princípios básicos orientadores de um trabalho pedagógico comprometido com a qualidade e a efetivação de oportunidades de desenvolvimento para todas as crianças" (OLIVEIRA et al., 2012, p. 33). Nesse viés, é necessário pensar o fazer pedagógico de forma a proporcionar às crianças maneiras diferentes de construir o conhecimento, a partir de uma concepção na qual a criança é protagonista, ator social e a infância uma categoria social (SARMENTO, 2011).

A elaboração do currículo e do processo de avaliação perpassa pela construção da ideia da criança como sujeito de direitos e nas "múltiplas interações que ela vai experimentando no mundo social" (OLIVEIRA et al., 2012, p. 36), viabilizando a construção do conhecimento por meio da vivência e da experiência, essenciais nas práticas da Educação Infantil.

O documento da Base Nacional Curricular Comum (BNCC) (BRASIL, 2017), no que se refere à Educação Infantil, designa os eixos estruturantes do currículo como: direitos de aprendizagem e desenvolvimento, os campos de experiência (Quadro 2), e também os objetivos de aprendizagem e desenvolvimento determinado para cada faixa etária. Vale ressaltar que, em abril de 2017, a versão final da BNCC foi encaminhada para o Conselho Nacional de Educação (CNE) para a elaboração do parecer e projeto de resolução da BNCC para então ser homologada. A partir de sua homologação, que o processo de formação e capacitação dos professores e as adequações curriculares necessárias nos sistemas de ensino serão realizadas, para que esta se efetive nas instituições escolares. 
Os direitos de aprendizagem e desenvolvimento prescritos na BNCC explicitam condições para as crianças aprenderem, evidenciando "[...] situações nas quais possam desempenhar um papel ativo em ambientes que as convidem a vivenciar desafios e a sentirem-se provocadas a resolvê-los, nas quais possam construir significados sobre si, os outros e o mundo social e natural" (BRASIL, 2017, p. 33). Para endossar o trabalho pedagógico em torno dos direitos propostos pela BNCC, foram estipulados cinco campos de experiência, nos quais são definidos os objetivos de aprendizagem e desenvolvimento. A concepção dos campos de experiência "acolhe as situações e as experiências concretas da vida cotidiana das crianças e seus saberes, entrelaçando-os aos conhecimentos que fazem parte de patrimônio cultural" (BRASIL, 2017, p. 36).

Quadro 2 - Educação Infantil na BNCC - Direitos de aprendizagem e desenvolvimento e campos de experiência (2017).

\begin{tabular}{|c|c|}
\hline \multirow{2}{*}{ Educação Infantil - BNCC } \\
\hline Eixos estruturantes & Direitos da criança \\
\hline \multirow{4}{*}{$\begin{array}{c}\text { Direitos de aprendizagem e } \\
\text { desenvolvimento }\end{array}$} & Conviver \\
\cline { 2 - 2 } & Brincar \\
\cline { 2 - 2 } & Participar \\
\cline { 2 - 2 } & Explorar \\
\cline { 2 - 2 } & Expressar \\
\hline \multirow{4}{*}{ Campos de experiência } & Conhecer-se \\
\cline { 2 - 2 } & Corponder e se desenvolver outro e o nós \\
\cline { 2 - 2 } & Traços, sons, cores e formentos \\
\cline { 2 - 2 } & Oralidade e escrita \\
\cline { 2 - 2 } & Espaços, tempos, quantidades, relações e \\
& transformações \\
\hline
\end{tabular}

Fonte: Brasil (2017, p. 23).

O processo de avaliação, relacionado aos direitos de aprendizagem proporcionados pelos campos de experiência, apresenta-se de maneira contínua, visando ao acompanhamento e à compreensão do desenvolvimento infantil. Nele, é preciso refletir a criança com sua singularidade, na diversidade e no seu contexto social. O professor precisa conceber que avaliar é "acompanhar a variedade de ideias e manifestações das crianças para planejar ações educativas significativas" (HOFFMANN, 2015, p. 30). 


\section{CAMINHOS TRAÇADOS PELA ANÁLISE DOCUMENTAL: DESAFIOS E POSSIBILIDADES}

Para esta análise documental utilizamos as DCNEI (BRASIL, 2009c), a versão final da BNCC (BRASIL, 2017) e o Caderno I - princípios e fundamentos da Educação Infantil da Rede Municipal de Educação de Curitiba (CURITIBA, 2016), para compreender as relações/interações entre a concepção de currículo e avaliação nos três documentos políticos.

De acordo com o Parecer 20/2009, o currículo "é concebido como um conjunto de práticas que buscam articular as experiências e os saberes das crianças com os conhecimentos que fazem parte do patrimônio cultural, artístico, científico e tecnológico" (BRASIL, 2009b, p. 6). Nota-se que as ideias de a criança vivenciar e experimentar estão presentes no documento, uma vez que tais vivências oportunizam a construção do conhecimento pela criança, quando mediada pelo professor.

Nesse sentido, a BNCC (BRASIL, 2017) apresenta os direitos de aprendizagem e desenvolvimento da criança, envolvendo a participação, a exploração, a brincadeira, a convivência, a livre expressão e as relações de identidade, dela mesma e dos grupos a que ela pertence. Todos os direitos elencados pela BNCC estão imbricados na experiência e vivência de cada criança. O Caderno I - princípios e fundamentos evidencia o conhecimento que a criança já dispõe, suas vivências e experiências, destacando a importância do professor refletir sobre esse conhecimento para planejar as ações pedagógicas para e com a criança, por conseguinte considerando o protagonismo infantil.

O Caderno I da RMEC (CURITIBA, 2016) destaca a polêmica entre cuidar e educar, a relação presente entre as duas ações que permeiam a concepção de educação infantil. O documento remete para o Parecer 20/2009 e para as DCNEI (BRASIL, 2009b; 2009c) no que estas "reafirmam a indissociabilidade do cuidado com o processo educativo", para esclarecer a necessidade de integração entre o cuidar e o educar. Na descrição sobre essa relação e da forma como ela deve acontecer, fica clara a abordagem referente à organização do professor dos tempos e espaços característicos da Educação Infantil, portanto, o planejamento das atividades que deve realizar. Já a BNCC (BRASIL, 2017) não aborda de forma explícita a relação "cuidar e educar", percebendo-se um silenciamento sobre essa indissociabilidade. 
A concepção de avaliação está intimamente ligada ao currículo, uma vez que os dois conceitos fazem parte do processo de aprendizagem da criança. Acerca dessa reflexão, as DCNEIs determinam que, pelo Parecer 20/2009, ao proceder a revisão das DCNEIs no que se refere à avaliação, estabelece

[...] Ela deve incidir sobre todo o contexto de aprendizagem: as atividades propostas e o modo como foram realizadas, as instruções e os apoios oferecidos às crianças formaram, o material oferecido às crianças, a forma como o professor respondeu às manifestações e às interações das crianças, os agrupamentos que as crianças formaram, o material oferecido e o espaço e o tempo garantidos para a realização das atividades. [...] a partir disso, [o professor pode] pesquisar quais elementos estão contribuindo, ou dificultando, as possibilidades de expressão da criança, sua aprendizagem e desenvolvimento, e então fortalecer, ou modificar, a situação, de modo a efetivar o Projeto Político-Pedagógico de cada instituição. (BRASIL, 2009b, p. 16).

No que diz respeito à avaliação, o Caderno I - princípios e fundamentos apresenta uma prática pautada na documentação pedagógica constituída no intuito de "promover uma prática docente reflexiva, que possibilite dar visibilidade as várias formas de compreender a criança, as suas realizações e os processos de aprendizagem que ocorrem durante o trabalho educativo" (CURITIBA, 2016, p. 77). Quanto ao processo de avaliação, indica que este deve ser a partir da observação e assentar-se em diversos registros, uma vez que a sua prioridade é o de acompanhamento, envolvendo também a análise do trabalho pedagógico e da prática reflexiva.

A organização desses registros pelo acompanhamento do processo, de acordo com o documento da RMEC, torna "visíveis as características de cada grupo, de cada família, oportunizando a construção de identidades, com diversas narrativas, incertas, que constituem histórias, dependendo do protagonista/interlocutor: crianças, profissionais, famílias e comunidade" (CURITIBA, 2016, p. 78). Dessa forma, enfatiza o processo que envolve o protagonismo infantil.

O texto da BNCC apresenta os objetivos de aprendizagem e desenvolvimento, como instrumentos balizadores e indicadores do processo de avaliação na Educação Infantil. O documento segmenta a Educação Infantil por faixa etária em três grupos, indicando determinados objetivos para cada um dos campos de experiência, porém, a redação do documento destaca que "esses grupos não 
podem ser considerados de forma rígida, já que há diferenças de ritmo na aprendizagem e no desenvolvimento das crianças que precisam ser consideradas na prática pedagógica" (BRASIL, 2017, p. 39).

Na análise do Caderno I- princípios e fundamentos, é notório assinalar que este é um documento norteador da prática na Educação Infantil, porém com a necessidade da complementação do Caderno II, ainda em construção, uma vez que depende da homologação da BNCC para então ser concluído. O texto do documento Caderno I vem sendo considerado acessível aos profissionais que atuam diretamente com a Educação Infantil, por apresentá-la em suas especificidades, como, por exemplo, a relação entre o cuidar e o educar, não veiculada na BNCC.

De acordo com as informações contidas na apresentação do Caderno I, sua elaboração foi coletiva, tendo iniciado em 2014, envolvendo a equipe do Departamento de Educação Infantil e representantes de pedagogos(as) da educação infantil dos núcleos regionais da educação. Sendo validado, no ano de 2016, por representatividade de profissionais que atuam na educação infantil da RME, envolvendo unidades, núcleos regionais e Departamento de Educação Infantil (CURITIBA, 2016, p. 11).

\section{PARA CONTINUAR A REFLEXÃO...}

A Educação Infantil, uma etapa singular na vida de crianças, tem como finalidade contribuir para o desenvolvimento integral da criança de até cinco anos de idade, em seus aspectos: social, físico, psicológico e intelectual. Nesse viés, o currículo na Educação Infantil precisa garantir a efetivação de práticas que articulem as experiências proporcionadas pelo ambiente escolar com os saberes da criança. A questão que conduziu este trabalho envolve o processo de avaliação e o currículo da Educação Infantil, pois, além de promover as práticas e o protagonismo infantil, como acontece o processo avaliativo incorporado a essas práticas? A avaliação na Educação Infantil está pautada no acompanhamento, na observação, no registro e na documentação, entendida como processo contínuo.

Análises de textos políticos subsidiam e "fornecem pistas sobre como as instituições explicam a realidade e buscam legitimar suas atividades" (SHIROMA; CAMPOS; GARCIA, 2005, p. 429), visto que, por meio do discurso, é possível perceber silenciamentos e situações de pertencimento de conceitos imbricados no contexto analisado. 
A elaboração de políticas para a Educação Infantil tem ganhado espaço ao longo da década de 1990 no cenário brasileiro, mas ainda tem um longo caminho a ser percorrido para que a efetivação dessas políticas seja concretizada. Dessa maneira, pensar um currículo para a Educação Infantil no qual as propostas sejam "de um cunho realmente pedagógico e voltadas não a uma criança abstratamente concebida, mas a crianças concretas" (KRAMER, 1987, p. 119), imbricado com o processo de avaliação, é fundamental para que o discurso encontrado nos documentos oficiais não esteja latente na realidade escolar.

Nas análises de textos políticos, é importante, no entanto, sempre lembrar as orientações de Ball que, em entrevista a Mainardes e Marcondes (2009), sublinha as formas de ação das políticas sobre as práticas. Afirma ele que elas não "se movimentam em direção à prática de maneira direta", uma vez que "o processo de traduzir políticas em práticas é extremamente complexo; é uma alternação entre [...] a modalidade primária, é textual, pois as políticas são escritas, enquanto a prática é ação, incluí o fazer das coisas". Para uma pessoa colocar em prática uma política, ela precisa "converter/transformar" as duas modalidades, pois a prática envolve "valores locais e pessoais e, como tal, envolve a resolução de, ou luta com, expectativas e requisitos contraditórios - acordos e ajustes secundários fazem-se necessários" (MAINARDES; MARCONDES, 2009, p. 305).

\section{REFERÊNCIAS}

BRASIL. Ministério da Educação. Secretaria da Educação Básica. Base Nacional Comum Curricular - versão final. Brasília, DF: MEC/SEB, 2017. Disponível em: <http:// basenacionalcomum.mec.gov.br/images/BNCC_publicacao.pdf>. Acesso em: 20 maio 2017.

. Lei n. 12.796, de 4 de abril de 2013. Altera a Lei n. 9.394, de 20 de dezembro de 1996, que estabelece as diretrizes e bases da educação nacional, para dispor sobre a formação dos profissionais da educação e dar outras providências. Diário Oficial da União, Brasília, DF, Seção 1, 5 abr. 2013, p. 1. Disponível em: <http://www2.camara.leg. br/legin/fed/lei/2013/lei-12796-4-abril-2013-775628-publicacaooriginal-139375-pl. html>. Acesso em: 1ㅇo out. 2018.

- Ministério da Educação. Conselho Nacional de Educação. Câmara de Educação Básica. Resolução CNE/CEB 5, de 17 de dezembro de 2009a. Fixa Diretrizes Curriculares Nacionais para a Educação Infantil. Diário Oficial da União, Brasília, DF, 18 dez. 2009. Disponível em: <https://www.mprs.mp.br/areas/gapp/arquivos/resolucao_05_2009_cne. pdf> . Acesso em: 20 maio 2017. 
BRASIL Ministério da Educação. Conselho Nacional de Educação. Parecer CNE/CEB n. 20, de 11 de novembro de 2009b. Revisão das Diretrizes Curriculares Nacionais para a Educação Infantil Diretrizes Curriculares Nacionais para a Educação Infantil. Diário Oficial da União, Brasília, DF, 12 dez. 2009. Seção 1, p. 14. Disponível em: http://portal.mec.gov. br/dmdocuments/pceb020_09.pdf. Acesso em: 01 out. 2018.

- Ministério da Educação. Conselho Nacional de Educação. Câmara de Educação Básica. Resolução CNE/CEB n. 5, de 17 dez. 2009c. Fixa Diretrizes Curriculares Nacionais para a Educação Infantil. Diário Oficial da União, Brasília, DF, 18 dez. 2009. Seção 1, p. 18. Disponível em: http://www.seduc.ro.gov.br/portal/legislacao/RESCNE005_2009.pdf. Acesso em: 01 out. 2018.

. Lei n. 9.394/1996, de 20 de dezembro de 1996. Estabelece as Diretrizes e Bases da Educação Nacional. Diário Oficial da União, Brasília, DF, n. 248, 23 dez. 1996. Disponível em: <http://www.planalto.gov.br/ccivil_03/leis/l9394.htm>. Acesso em: 10 out. 2018..

. Lei n. 8.069, de 13 de julho de 1990, e legislação correlata [recurso eletrônico]. Estatuto da Criança e do Adolescente . 9. ed. Brasília, DF: Câmara dos Deputados, 2010. (Série legislação; n. 83). Disponível em: <http://www.crianca.mppr.mp.br/arquivos/File/ publi/camara/estatuto_crianca_adolescente_9ed.pdf>. Acesso em: 1o out. 2018.

. Presidência da República. Constituição da República Federativa do Brasil de 1988. Disponível em: <http://www.planalto.gov.br/ccivil_03/constituicao/constituicao. htm>. Acesso em: 1o out. 2018.

CAMPOS, Maria Malta. A legislação, as políticas educacionais de educação infantil e a realidade: desencontros e desafios. In: MACHADO, Maria Lúcia de A. (Org.). Encontrose desencontros em educação infantil. São Paulo: Cortez, 2002. p. 27-33.

CURITIBA. Prefeitura Municipal de Curitiba. Secretaria Municipal de Educação. Educação Infantil - Caderno I: princípios e fundamentos. 2016. Disponível em: <http://www. educacao.curitiba.pr.gov.br/conteudo/curriculo-da-educacao-infantil/8229>. Acesso em: 20 maio 2017.

EYNG, Ana Maria. Currículo e avaliação: duas faces da mesma moeda na garantia do direito à educação de qualidade social. Revista Diálogo Educacional, Curitiba, v. 15, n. 44, p. 135-57, 2015.

FAIRCLOUGH, Norman. Análise crítica do discurso como método de pesquisa científica. Linha d'Água, São Paulo, v. 25, n. 2, p. 307-29, 2012.

FAIRCLOUGH, Norman. Discurso e mudança social. Revisão técnica e prefácio à edição brasileira Izabel Magalhães. Brasília, DF: Editora Universidade de Brasília, 2001.

FAVORETO, Elizabeth Dantas de Amorim. Creche e pré-escola: representações Sociais de Estudantes de Pedagogia e Políticas para Educação Infantil. 194f. Dissertação (Mestrado em Educação) - Pontifícia Universidade Católica do Paraná. Curitiba, PR, 2013. 
HOFFMANN, Jussara. Avaliação e educação infantil: um olhar sensível e reflexivo sobre a criança. 20.ed. Porto Alegre, RS: Mediação, 2015.

KRAMER, Sonia. A infância e sua singularidade. In: BRASIL, Ministério da Educação. Ensino Fundamental de nove anos: orientações para a inclusão da criança de seus anos de idade. Brasília, DF: Ministério da Educação, Secretaria da Educação Básica, 2007.

. A política do pré-escolar no Brasil: a arte do disfarce. 3. ed. Rio de Janeiro: Dois Pontos, 1987.

MAINARDES, Jefferson; MARCONDES, Maria Inês. Entrevista com Stephen J. Ball: um diálogo sobre justiça social, pesquisa e política educacional. Educação \& Sociedade, Campinas, SP, v. 30, n. 106, p. 303-18, jan./abr. 2009. Disponível em: <https://www.cedes. unicamp.br/publicacoes/edicao/84>. Acesso em: 20 jun. 2017.

MORAES, Roque. Uma tempestade de luz: a compreensão possibilitada pela análise textual discursiva. Ciência \& Educação, Bauru, v. 9 n. 2, p.191-211, 2003.

OLIVEIRA, Stela Maris Lagos. A legislação e as políticas nacionais para a educação infantil: avanços, vazios e desvios. In: MACHADO, Maria Lúcia de A. (Org.). Encontros e desencontros em Educação Infantil. São Paulo: Cortez, 2002. p. 35-42.

OLIVEIRA, Zilma Ramos de et al. Um campo de disputa e concepções. In: OLIVEIRA, Zilma Ramos (Org.). O trabalho do professor na Educação Infantil. São Paulo: Biruta, 2012. p. $19-42$.

PÉREZ, Justa Bejarano. O currículo da educação infantil. In: SACRISTÁN, José Gimeno. Saberes e incertezas sobre o currículo. Porto Alegre: Penso, 2013. p. 336-54.

PIAGET, Jean; INHELDER, Bärbel. A psicologia da criança. Rio de Janeiro: Difel, 2003.

ROSEMBERG, Fúlvia. Educação Infantil pós-LDB: avanços e tensões. In: SOUZA, Gisele de (Org.). Educar na infância: perspectivas histórico-sociais. São Paulo: Contexto, 2010. p. 171-86.

SARMENTO, Manoel Jacinto. A Sociologia da infância e a sociedade contemporânea: desafios conceituais e praxeológicos. In: ENS, Romilda Teodora; GARANHANI, Marynelma Camargo. Sociologia da Infância e a formação de professores. Curitiba: Champagnat, 2011. p. 13-46.

SHIROMA, Eneida Oto; CAMPOS, Roselane Fátima; GARCIA, Rosalba Maria Cardoso. Decifrar textos para compreender a política: subsídios teórico-metodológicos para análise de documentos. PERSPECTIVA, Florianópolis, v. 23, n. 2, p. 427-46, jul./dez. 2005. Disponível em: <http://www.ced.ufsc.br/nucleos/nup/perspectiva.html>. Acesso em: 10 maio 2017. 


\section{Sobre as autoras:}

Romilda Teodora Ens: Pós-Doutora pela Universidade do Porto, Portugal. Doutora em Educação pela Pontifícia Universidade Católica de São Paulo. Professora Titular do Programa de Pós-Graduação em Educação, Mestrado e Doutorado da Pontifícia Universidade Católica do Paraná (PUCPR), na linha História e Políticas da Educação. Pesquisadora associada da Fundação Carlos Chagas. Lidera o grupo de pesquisa Políticas, Formação de Professores, Trabalho Docente e Representações Sociais (POFORS) na PUCPR, que integra a Cádetra da UNESCO sobre Profissionalização Docente, coordenada pelo Centro Internacional de Estudos em Representações Sociais, Subjetividade e Educação da Fundação Carlos Chagas (CIERS-ed). Participa do ReLePe e NEARS/PUC/SP. E-mail: romilda.ens@gmail.com

Jaqueline Salanek de Oliveira Nagel: Mestre em Educação e Doutoranda em Educação pela Pontifícia Universidade Católica do Paraná (PUCPR), na linha História e Políticas da Educação. Participa do Grupo de Pesquisa Políticas, Formação do Professor e Representações Sociais (POFORS). Possui graduação em Pedagogia pela Universidade Federal do Paraná. Especialista em Educação infantil pela Pontifícia Universidade Católica do Paraná e em Gestão e Educação Ambiental pela SPEI. É Pedagoga da Rede Municipal de Ensino de Curitiba, atuando no Departamento de Ensino Fundamental, DEF, na gerência de Gestão Escolar. E-mail: jaquenagel@gmail.com

Édina Dayane de Lara Bueno: Mestre e Doutoranda em Educação pela Pontifícia Universidade Católica do Paraná (PUCPR), na linha de pesquisa de história e política de educação. Graduada em Pedagogia pela PUCPR. Participa do grupo de pesquisa Políticas, Formação de professor e Representações Sociais (POFORS). E-mail: dayanebuenocouto@yahoo.com.br

\section{Recebido em fevereiro de 2018}

Aprovado em maio de 2018 
